\title{
Curriculum development: panacea or poison?
}

\author{
Terence Nigel Mitchell*
}

First publication online: 30 June 2015

\begin{abstract}
The November 2014 issue of the Tuning Journal appeared under the theme "Policy and Implementation: Actions for Curriculum Reform". This article is a personal reflection on the role of curricula in achieving the aims of the European Higher Education Area (EHEA) and beyond. Its background is the postulate that the most important goals of the Bologna Process are essentially the improvement of mobility and recognition at all levels of higher education. Curricula can be used to encourage mobility and recognition or to hinder them, but as an element of the education process they have been treated very unevenly during the development of the EHEA. Well-designed curricula are vital, but must not be misused. In the European climate of today, the development of regional, national or even international curricula is neither possible nor necessary.
\end{abstract}

Keywords: Curricula; learning outcomes; mobility; recognition; Bologna.

\section{Introduction}

Every degree course has a curriculum. Logical, but not always true. Not in all subjects in all countries of the European Higher Education Area. Not pre-1999. But we are now living in a "Brave New World". So where are we now?

After fifteen years, it is worth looking back at the Bologna declaration of June $1999,{ }^{1}$ which has had such a dramatic influence on higher education in Europe and indeed, directly and indirectly, throughout the world. The expressed aims of the 29 ministers who signed the Declaration (joined in later stages by 17 more) were only six in number. They were brief and concise, expressed in only 248 words.

* Terence Nigel Mitchell (terence.mitchell@tu-dortmund.de) is a retired professor of Chemistry, TU Dortmund University, Germany.

1 “The European Higher Education Area: Bologna Declaration,” accessed June 9th, 2015, http://www.magna-charta.org/resources/files/BOLOGNA_DECLARATION.pdf. 
Point one deserves to be quoted verbatim: "Adoption of a system of easily readable and comparable degrees, also through the implementation of the Diploma Supplement, in order to promote European citizens employability and the international competitiveness of the European higher education system".

At that time degrees within Europe were not easily readable and certainly not comparable, except (on paper) for the doctoral degree, which we shall come to below. The easiest form of mobility was to move to another institution at the end of one's "first degree" in order to study for a doctoral degree. But these first degrees had a host of different titles (not easily readable) and were of different lengths (not comparable).

While this first point in the Declaration made it clear to national higher education systems that modification would be necessary, in itself it did not sound threatening. The real dynamite in the Declaration was point two:

Adoption of a system essentially based on two main cycles, undergraduate and graduate. Access to the second cycle shall require successful completion of first cycle studies, lasting a minimum of three years. The degree awarded after the first cycle shall also be relevant to the European labour market as an appropriate level of qualification. The second cycle should lead to the master and/or doctorate degree as in many European countries.

These 70 words were the central point in the Declaration. The new "first" or "undergraduate" cycle was then unknown except for a few countries on the geographical fringes of Europe. Three-year degrees were also practically unknown across the Bologna area. The idea that a university degree should be "relevant to the European labour market" was (and still is) anathema to many university teachers. And the third sentence would have been completely unclear to many readers: "the second cycle should lead to the master AND doctorate degree" would mean that there should be THREE cycles (now, as we know, the Bologna process indeed includes three). "The second cycle should lead to the master OR doctorate degree" would mean that the "first cycle" could lead directly to a doctorate. A threeyear degree as the prelude to a doctorate? When I studied in the UK (19611967) this is exactly what I experienced: it was the norm. But again such an idea was then anathema to very many university teachers throughout Europe.

Point three was much more concrete, calling as it did for "the establishment of a system of credits - such as in the ECTS system - as a proper means of promoting ... mobility". Let us remind ourselves that ECTS (the European Credit Transfer System) was initially established in 1988 and 
expanded in stages. By the time the Bologna Declaration was signed, nearly 1300 higher education institutions (HEIs) had already introduced ECTS or had (on paper at least) committed themselves to doing so. ${ }^{2}$

For comparison, in 2011 the total number of HEIs in the EU-28 countries was around 4000, ${ }^{3}$ while the Russian Federation, a Bologna signatory, had over 1100 educational institutions of university level in that year. ${ }^{4}$

ECTS is now THE credit transfer system in the European Higher Education Area (EHEA), and has been renamed "Credit Transfer and Accumulation System". It has undergone various developments in the interim (not all of them positive), and remains highly contentious at departmental level in very many institutions.

The last three points dealt with the promotion of:

- Mobility for teachers and students.

- European cooperation in quality assurance.

- The necessary European dimensions in higher education.

While all three were vital for the construction of the planned EHEA, they will probably not have appeared contentious to the great majority of readers.

A closer look at point six does however show that it would turn out to contain one of the stumbling blocks to the creation of the EHEA: "Promotion of the necessary European dimensions in higher education, particularly with regards to curricular development, inter-institutional co-operation, mobility schemes and integrated programmes of study, training and research".

\section{European Dimensions?}

Before the signing of the Declaration there were no European dimensions in higher education at all, and certainly not in the area of curricular development. But the point to be made here is that curricula were recognised as an aspect of university internationalisation that needed to be taken into account. Institutions did of course cooperate with each other in various ways and ERASMUS was there to deal with mobility. The idea of "integrated

2 "ECTS - European Credit Transfer System," accessed January 23, 2015, http://www. aic.lv/ace/ace_disk/ECTS/Abo_ECTS.htm.

3 "European Commission, Eurostat. Tertiary Education Statistics," accessed January 23, 2015, http://ec.europa.eu/eurostat/statistics-explained/index.php/Tertiary_education_statistics.

4 "Russian Education HE Statistics," accessed January 23, 2015, http://www.russianenic. ru/english/rus/statenhe.html. 
programmes of study, training and research" does not seem to have been taken further in the Bologna Process.

When read quickly, point six in fact sounds reasonable and logical. The new degree structures would make student mobility much easier, so that the setting up of multitudinous mobility schemes via inter-institutional cooperation agreements would become feasible because of the presence of curricula which were valid across European countries. The "integrated programmes" could perhaps become almost a by-product which would deal with mobility at the doctoral level (which the Declaration did not however actually include).

One of the rationales behind Tuning was that the creation of international Subject Area Groups (SAGs) would promote discussions which would help to create a European "way of thinking" in higher education. Tuning, as we now know, was hugely successful and spread beyond Europe to various regions of the world. But at the beginning it was a small, tender plant which needed nourishing by its SAGs.

How do we actually develop curricula with a European dimension? Well, if the student was planning to take a degree in "European Studies" one might think that curricular aspects should not be a stumbling block in creating degree programmes. The document "Reference Points for the Design and Delivery of Degree Programmes in European Studies" 5 produced by the relevant SAG does include the word "curriculum" in its Conclusions:

Since the general objective of any European core curriculum must be to keep a rich diversity of teaching and learning, attempts to bring about standardisation must be avoided. Yet the group was also convinced that such standardisation is necessary neither for student mobility nor for the portability of degrees. We believe that there is sufficient comparability in the core elements, and in the learning outcomes sought by the degrees, for these objectives to be realised. Students should gain the core competences in any European studies programme.

One should note that the document talks of a "core curriculum". So where do we find this in the document? On p. 24 we find the following:

Core of European studies for first cycle

- Knowledge of ideas/concepts of Europe.

- Knowledge of European integration.

5 "Reference Points for the Design and Delivery of Degree Programmes in European Studies," accessed January 23, 2015, http://www.unideusto.org/tuningeu/images/stories/ Publications/EUROPEAN_STUDIES_FOR_WEBSITE.pdf. 
- Knowledge of European institutions and decision making policies.

- Knowledge of EU policies.

- Knowledge of Europe's changing role in the world.

Five points, each qualified by the highly abstract phrase "knowledge of". One has the feeling that the SAG shied away from producing anything which could be recognized as an attempt to define a curriculum!

Perhaps, however, a differentiation is made in the Core for the second cycle? No, not at all. The same five points are present at second cycle level. The first and second cycle differ only in the "abilities" listed, which are not strictly curricular (input) aspects but outcome aspects.

All this is not intended to criticise the European Studies SAG in any way, but to demonstrate that, for whatever reasons, they did not wish to go down the road of curriculum development. For them it was apparently closer to a poison than a panacea.

\section{The Wrong Example?}

European Studies is a relatively young discipline, and perhaps curriculum development will play a role in its development in the future. Many other disciplines have clearly defined structures which will be the same across Europe. One might take as an example a registered profession, where rigid definitions of the education and training process are present (although these may well be outdated).

Medicine is an obvious case. The relevant Tuning Medicine document ${ }^{6}$ contains the following statement on curricular development: "Tuning is not an attempt to achieve rigid curricular uniformity - indeed one advantage of an outcomes-based approach is that diversity in educational process and curriculum structure can be preserved".

No "European curricula", but diversity in curriculum structure. The group which did the work in this area has defined "12 major (level 1) outcomes" and goes on to say that: "The Level 1 outcomes and "Medical professionalism' are suitable for implementation as 'curriculum themes'...". The list of these outcomes is preceded by the highly abstract phrase "Graduates in medicine will have the ability to:".

One could go on searching for information on the way curriculum development is seen by the various groups involved in Tuning, or indeed in

6 “The Tuning Project (Medicine)," accessed January 23, 2015, http://www.tuningmedicine.com/use.asp. 
the development of teaching in other subjects. But this article is not intended to provide a statistical survey.

Let me own up to being a chemist and turn to my own discipline (I am a former chair of the chemistry Subject Area Group or SAG). Early on in our Tuning work, we, like others, realised that universities in many countries really needed concrete help in turning their (generally) "old" five-year degrees into the "new" Bachelor and Master structures, which at that time appeared to be destined to involve a three-year and a two-year degree. Diversity in this respect has since re-emerged in the EHEA.

In the course of time, Tuning developed a methodology, which is described on the Tuning Europe website. ${ }^{7}$ This included a model for designing, implementing and delivering curricula. Step 5 in the process is defined as "Translation into the curriculum: content (topics to be covered) and structure (modules and credits)".

Naturally, the chemistry SAG was asked to look at points relevant to curriculum structure and development, but shied away from the idea of a model curriculum structure for chemistry first cycle degrees. Instead, it came up with what we called a "framework" for a first cycle degree, which we called Eurobachelor ${ }^{\circledR}$ (we did in fact trademark it later ${ }^{8}$ ).

During our initial work on the framework, we made the mistake of trying to attach numbers of ECTS credits to the major sub-disciplines of chemistry, i.e. to divide up the 180-credit "cake" into several large pieces. We were immediately attacked by the European organisation representing one of these sub-disciplines, which had already gone much further than we had thought of doing by drawing up a "Eurocurriculum" for their area. This had unfortunately been devised on the basis of a larger number of ECTS credits than we had tentatively allocated to it!

So we quickly realised that our framework should contain as few numbers as possible, and leave individual institutions to divide up the credit cake as they wished (subject only to two limitations, which have never really been challenged).

Thus the Eurobachelor ${ }^{\circledR}$ and the Euromaster ${ }^{\circledR}$ which followed it ${ }^{9}$ are NOT "model curriculum structures" but an attempt to provide a common way of looking at degree structures, the goals of course being mobility and

7 "Tuning Educational Structures in Europe: Tuning Methodology," accessed January 23, 2015, http://www.unideusto.org/tuningeu/tuning-methodology.html.

${ }^{8}$ Evangelia Varella, "The European Quality Labels in Chemical Sciences: applying the Tuning Methodology in quality assurance," Tuning Journal for Higher Education 1, $\mathrm{n}^{\circ} 2$ (2014): 369-385, accessed January 23, 2015, http://www.tuningjournal.org/index.php/tuning/ article/view/31/19. 
recognition. These, as we know, are still often a huge problem in the EHEA.

\section{Do Mobility and Recognition profit from Common Curricula?}

There is a simple answer to this question: NO! They profit from openmindedness on the part of responsible faculty members and the will to accept that others teach differently than they themselves do. Am I trying to say that colleagues are often very narrow-minded in this respect? Yes. But such colleagues will not be readers of this Journal.

Now that the construction of the EHEA is considerably advanced, a problem arises in innumerable cases. The "cake" to which I referred above, however many ECTS credits it may comprise, has been divided up into what we are supposed to call "modules", but which when we are honest are often just course units which may or may not have been subsumed into modules. I will not defend or attack what institutions are doing in this article, though as a former ECTS counsellor and Bologna Expert I do have clear notions as to what still needs to be done, and I will return to this point in the next section.

But what of the mobile student? He or she goes abroad and gains ECTS credits, hopefully on the basis of a Learning Agreement which both sides took seriously when it was drawn up. But as far as recognition is concerned we all know the "arguments against", such as:

- The module/course A which they have only carries 8 credits, while ours carries ten.

- Their module B does not cover the topic X at all.

- In their module $C$ they use textbooks which I have never heard of.

- ... and permutations, variations and combinations thereof.

The problem of course is that individual curricula can be very different (and individual academics very difficult).

And what of the bachelor graduate who wishes to move to another institution to do a Master's degree? In an ideal world this should not be a problem for mobility within the EHEA. But we do not live in an ideal world. I remember an Italian member of the physics SAG in Tuning telling me in all seriousness that his institution would only accept a physics Bachelor from another institution if he/she had at least 10 credits in Nuclear Physics. For Nuclear Physics read "the French Revolution", "Shakespeare", "19 $9^{\text {th }}$ Century 
Operas", or whatever topic you can think of instead in your own subject. Again, the fault lies with individual curricula.

\section{Curricula and Accreditation}

The latest stage in the Bologna Process was the Ministerial Meeting held in Yerevan very recently. One of the products of this meeting was the adoption of the revised version of the European Standards and Guidelines (ESG). ${ }^{9}$ On page 5, there is a section called ESG: Purposes and principles. One of these being "They support mutual trust, thus facilitating recognition and mobility within and across national borders". I would submit that this is not true. The ESG are interpreted by national QA bodies, which are not really interested in the international aspects of their work at all. One result of this is that the accreditation of Joint Degrees has until now been a problem of the highest order. Although the chemists accreditation body ECTN, because of its international nature, has no problem in dealing with such programmes, however many institutions in however many countries they may involve.

In fact, unless I was careless in my reading, the new revised ESG use the word "curricula" only once, in the introduction! Thus curricula appear not to be a feature of the standards against which degree courses are measured. There are no criteria against which curricula are judged.

In fact, the ESG are not "European" at all! They are merely a set of rules which govern the work of accreditation agencies. They do nothing towards facilitating mobility and recognition. Accreditation agencies are, for example, not even requested to make use of international peers in their reviews. In fact, one large national accreditation system is allowed by the ESG to simply require institutions to tick boxes without the necessity of site visits. All this leads to the next question:

\section{Do We Still Need Curricula?}

One might think that in this Brave New World of learning outcomes it is possible to do without curricula at all. Simply sit down at a drawing

9 "Revised ESG approved by the Ministerial Conference in Yerevan, on 14-15 May 2015," accessed June 9 $9^{\text {th }}, 2015$, https://www.eqar.eu/fileadmin/documents/e4/ESG_ endorsedMay2015.pdf. 
board and list the learning outcomes which a degree in subject $\mathrm{X}$ is intended to provide. Then give the student a list of these outcomes, together with a list of the modules on offer, each module in the list having a short description which includes the learning outcomes which it is intended to promote. And let them do their selection and their sums so that they come out at the end with 180 ECTS credits (or however many the particular degree carries).

No, curricula are important, nay vital. Faculty are responsible for setting up a curriculum which permits the student to achieve the defined learning outcomes. They define what is taught in years 1,2 or 3 . They decide which modules are compulsory and which elective. But today they cannot (or should not be allowed to) do their work without taking learning outcomes as the background to and raison d'être for this work.

Curricula are local, and should be so. They reflect the academic profiles of the teaching staff, and the defined profile of the institution. They cannot be devised on a regional, national, or international basis. But the relevant learning outcomes can and should be international in nature.

Tuning America, which of course came on to the stage much later than the original Tuning Europe, expresses the present Tuning philosophy very clearly: 10 "Tuning, however, does not attempt to standardize curricula. As has been noted already, Tuning is a faculty-driven process that identifies an explicit core of competencies and learning outcomes. The core outcomes are not an attempt to standardize curricula or to create some sort of statewide or national curriculum".

\section{Was It a Mistake for the Bologna Declaration to Refer to Curricula?}

In the light of what has been written above, the reader would be forgiven for expecting that my answer would be a resounding yes. But that is not the case. The Bologna Declaration is a concise document which has revolutionised university education across Europe and beyond. None of the later Bologna communiqués can compare with its power and immediacy.

The Tuning Project was set up as a reaction to the Bologna Declaration. The latter was signed by ministers of education, who returned home and decided how (if at all) their national education systems should deal with

10 “Degree Qualifications Profile (DQP). What is Tuning?,"accessed January 29, 2015, http://degreeprofile.org/press_four/wp-content/uploads/2014/12/What-is-Tuning.pdf. 
the Bologna goals. Some (for example the Netherlands) told institutions to get down to work on implementing Bologna straightaway, while others (like Germany with its decentralised federal structure) tended to do nothing. But the goal of Tuning was to help institutions to react to the Bologna proposals.

And where would institutions need the most help? With "Adoption of a system essentially based on two main cycles, undergraduate and graduate". The then Tuning Management Committee saw itself with an apparently huge agenda and asked its SAGs to carry out various tasks which were devised to get faculty talking across national barriers. This worked, and the rest is history.

But, with the benefit of hindsight, more could and should have been done towards dealing with the "two main cycles". The "first" cycle, now generally known as the Bachelor, was present pre-Bologna in the UK and Ireland, and in Finland. Almost all the other signatory countries started with a long fouror five-year degree. So to them and to their academics the introduction of a shorter degree meant that they would have to offer a "lower quality" degree, often characterised as being an "Anglo-Saxon" model.

Tuning in its initial SAGs could have been used as a discussion platform for devising logical ways of distinguishing between Bachelor and Master and their qualification levels. Based not just on learning outcomes, which were at that time very much an abstract quantity to academics (and very often still are, even today) but also on curricular aspects. European curricular reform could at that time have been the subject of useful debate in terms of distinguishing between the first and second cycles. With respect to the first cycle, this would admittedly have necessitated a considerable amount of input from UK, Ireland and Finland representatives, but to find the common denominators in these systems would have provided a starting point for other countries to join the discussion. And the first cycle was the problematic one for countries with no experience.

The chemistry SAG in Tuning had the advantage, like the physics SAG, that it could call upon academics from its already well-established Thematic Network to do work on Bologna which in some cases had already been the subject of internal discussion. Its members already knew each other. Thus it was able to get off the mark very quickly. We realised that institutions would need help in coming to grips with the Bachelor concept, and our discussions led to the Eurobachelor ${ }^{\circledR}$ concept mentioned above. We chose the term "Eurobachelor" because we felt that it could help to give a Bachelor graduate from Europe an identity for those outside Europe who did (then) not know that such an animal existed and what it represented. 
Our hope was that other disciplines within Tuning would seize on this name and go down a similar type of route as we had, but this was not to be. (The trademarking took place later).

The reader is asked to note that the Eurobachelor ${ }^{\circledR}$ framework $^{11}$ is NOT a curriculum model. It has a descriptor to set the stage (as in "Dublin Descriptor", but ours were written in Budapest). The closest it comes to thinking in a curricular manner is that it has a list of 15 topics which we considered as being common ground for a chemistry first cycle degree. This list was adapted from the British QAA benchmarks of 2001. But (as mentioned above) no type of quantification as to numbers of ECTS credits allocated is included. We do define a minimum "core" for the course, but institutions tend to think we should have set the core volume $(50 \%$ of the total number of ECTS credits) much higher. The goals of the framework are the improvement of mobility and recognition, two key aspects of the Bologna Process.

\section{The "Successful" Transition to Bachelor and Master}

The EHEA is (more or less) in place and the successful transition from the "old long degrees" (such as the German Diplom) to Bachelor and Master is well on its way in some countries and complete in others.

This is what the Bologna ministers would like to believe: the European Students Union might well not agree. Progress has been made at a formal level, for example with the ministerial approval of the European Qualifications Framework in 2005. A useful short introduction to this framework appeared in 2008. ${ }^{12}$

Pages 4 and 5 of the above document contain the "Dublin Descriptors", which seek to make a distinction between the three cycles of the Bologna Process. They are of necessity highly abstract, but nevertheless form the background to developing new Bachelor and Master programmes.

A next logical step would be to formulate such descriptors at a subject level, as was done by the chemistry Tuning SAG. Our descriptors form part

11 Terence Mitchell and Richard Whewell, "ECTN. Employability of First Cycle Graduates. The Chemistry 'Eurobachelor ${ }^{\circledR}$," accessed January 23, 2015, http://ectn-assoc.cpe. fr/chemistry-eurolabels/n/lib/1_eb/2-Eurobachelor_Documentation.pdf.

12 "The Bologna Framework and National Qualifications Frameworks - an Introduction," accessed January 23, 2015, http://www.ehea.info/Uploads/QF/Bologna_Framework_and_ Certification_revised_29_02_08.pdf. 
of the Eurobachelor ${ }^{\circledR}$ framework. It appears that not much work has been done in this area in other disciplines.

The language of descriptors is however not the language of academics, while quality assurance agencies and ministries are quite enamoured of them. I can provide an example of the difference between the points of view of the QA/ministry side and the academic side. The Joint Quality Initiative informal group, which was responsible for drafting the Dublin Descriptors, consisted mainly of representatives of Quality Assurance bodies and ministries. ${ }^{13}$ However, I happened to be present (as a representative of the German Accreditation Council) at the meeting which produced the descriptor for the third cycle. Naturally a draft was circulated, and to my surprise this did not contain the word "research", although we were dealing with the doctoral cycle! Luckily I was supported at once in my objection to this omission by a second academic colleague (whose name unfortunately escapes me), and after some debate we succeeded in incorporation of this vital word in the first three sentences.

But I digress. At the beginning of this section I specifically used the phrase "successful transition". The question here is to how one measures success. The mere replacement of a long degree by two consecutive shorter ones is not a measure of success, but a demonstration of political correctness. Innumerable students will have gone down the Bachelor/Master road since this was opened, and a very high proportion of these will have been frustrated and angry in turns. Why? Because the letter of Bologna has been followed, but not the spirit.

Bologna is about mobility, Bologna is about recognition. The Bologna transition to the new degree structure required curriculum reform, or curricular modification. And in too many cases departments or faculties first stuffed the Bachelor degrees with as much material as possible from the old long degree, did a quick calculation of how they could distribute ECTS credits, and then realised that they had no idea what to put into the Master programmes. Learning outcomes, if at all, were brought in later under pressure from outside. Assessment methods were as before.

Many of my readers may object to this analysis. Perhaps this is not the case in their institution or their department. And they are likely to be right,

13 "Draft 1 working document on JQI meeting in Dublin on 18 October 2004. Shared 'Dublin' descriptors for Short Cycle, First Cycle, Second Cycle and Third Cycle Awards," accessed June 9 2015, http://paginas.fe.up.pt/ sfeyo/Docs_SFA_Bologna/120_Ref\%20 Doc_20041018\%20\%5BJQIG\%20Dublin\%20Descriptors\%5D.pdf. 
because they are reading the Tuning Journal, which means that they themselves are interested in educational reform and progress.

In November 2013 the German Hochschulrektorenkonferenz passed a resolution on "European Study Reform", which they were kind enough to translate into English. ${ }^{14}$ The passages in inverted commas below are recommendations from this resolution (in the original these were in italics, but in the translation no italics were used, which makes it difficult to identify the recommendations clearly).

On recognition: "To improve the recognition process, the Universities should ensure that the staff at the Universities are sufficiently familiar with the Lisbon Recognition Convention, the function and application of ECTS and the Diploma Supplement".

And again:

The university staff occupied with recognition must adopt the principle of generous recognition based on learning outcomes and skills, as represented by the Lisbon Recognition Convention. This involves not only applying the convention to studies carried out abroad, but also at the national level, for example, when students switch universities within Germany or during the transition from a bachelor's to a master's course.

Mobility and recognition:

Europe has taken the first step with the Lisbon Recognition Convention. From a European perspective, however, the German Universities must improve the framework for mobility and the recognition process. Each university has individual responsibility for this. University leadership should therefore work closely with faculties and departments to remove formal, procedural and content-related obstructions to mobility and endeavour to deliver appropriately short preparation times for periods in other countries.

On curricula:

Universities and the universities in particular should separate the bachelor's and master's content more than they have to date and encourage the students to try to tailor their study pathways individually, so that they do not necessary reflect the 180+120 ECTS credits model dominating the universities. ......Transition to a master's at another type of university should be supported and also be viewed as an opportunity by the

14 “HRK German Rectors' Conference. European Study Reform. Recommendation of the 15th General Meeting of the HRK, 19 November 2013," accessed June $9^{\text {th }}, 2015$, http://www. hrk.de/resolutions-publications/resolutions/resolution/convention/european-study-reform/. 
Universities. The same applies to transitions to a master's in subjects that are not completely compatible. To do this, the Universities, provided they have the resources, should apply their admission procedures with greater leniency. Bachelor's and master's should not be assessed by their duration nor the number of ECTS credits, but by the skills that are learnt.

On assessment of learning outcomes:

University leadership should ensure than the university staff and students are familiar with the fundamental ideas of skill-oriented teaching and examining. This requires teachers to enter into dialogue with others, the provision of appropriate career development and the time and space to work on developing teaching and examinations.

Back to recognition: “...... Universities should adjust course organisation (advice, supervision, recognition of credits on moving from one subject or university to another, the feasibility of completing a study programme, etc.) to the reality of the students".

And finally curricula again: "Universities must review their courses in terms of the feasibility of their successful completion within a certain period and of the unwelcome effects of compaction (lack of options), and where necessary modify them".

These recommendations make it clear that "a lot still has to be done". I am not singling out Germany for criticism, but simply using an example which is familiar to me to demonstrate the problems which are still being faced in many countries, many institutions and many subjects.

\section{Conclusion}

Curricula are for local use, not regional or international use. Of themselves they need not be a Bologna concern, and their reform neither a panacea nor a poison. However, in the brave new Bologna world they can no longer be seen on their own, but must be linked with many other factors, and in particular with learning outcomes and ECTS credits (and the Diploma Supplement, an important but still flawed tool of the EHEA), as has been discussed above. Curricula determine the "input" which is designed to lead to "output" in the sense of (assessed) learning outcomes. They should really be prefaced in all cases by a Descriptor, to which reference can be made when they are being judged by external experts. A carefully-written Descriptor can take into account the competences to be achieved and the levels of such competences. Curricula must be written in terms of modules, each of these being accompanied by their foreseen learning outcomes. 
In terms of mobility and recognition, the restrictive use of the mere content of curricula (and ECTS credits) as a sole or main measure of the quality of degree courses can certainly poison the atmosphere to which students across Europe are still very often subjected.

\section{Copyright}

Copyright for this article is retained by the Publisher. It is an Open Access material that is free for download, distribution, and or reuse in any medium only for non-commercial purposes; provided any applicable legislation is respected, the original work is properly cited, and any changes to the original are clearly indicated. 